\title{
Nitrogen-Doped Carbon Quantum Dot-Anchored Hydrogels for Visual Recognition of Dual Metal ions through Reversible Fluorescence Response
}

Jianbo Huang ${ }^{\mathrm{a}}$, Xin Liu ${ }^{\mathrm{a}, *}$, Lijun $\mathrm{Li}^{\mathrm{a}}$, Sheng Chen ${ }^{\mathrm{a}}$, Jun Yang ${ }^{\mathrm{a}}$, Jipeng Yan ${ }^{\mathrm{b}}$, Feng $\mathrm{Xu}^{\mathrm{a}}$, Xueming Zhang,*

a Beijing Key Laboratory of Lignocellulosic Chemistry, Beijing Forestry University, 35 Qinghua East Road, Haidian District, Beijing 100083, China.

${ }^{\mathrm{b}}$ Advanced Biofuels and Bioproducts Process Development Unit and Biological Systems and Engineering Division, Lawrence Berkeley National Laboratory, Emeryville, California 94608, United States.

Total number of pages (including cover): 8

Total number of figures: 7

Total number of tables: 3

* Corresponding authors. E-mail address: xm_zhang@bjfu.edu.cn Tel.: +86-01062336189.

*Corresponding authors. E-mail address: xinliu0815@163.com Tel.: +86-01062336189. 


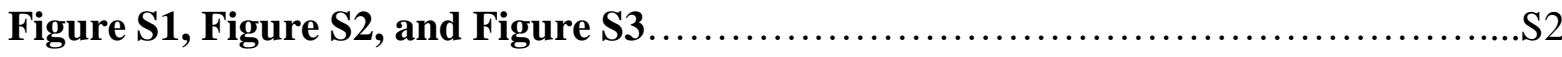

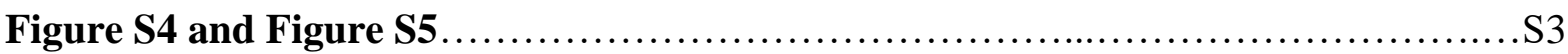

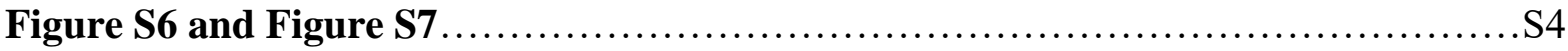

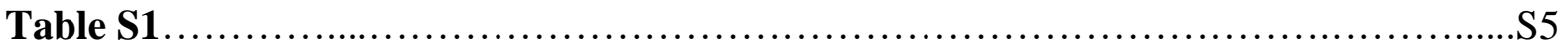

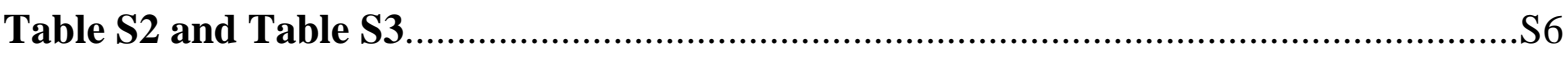

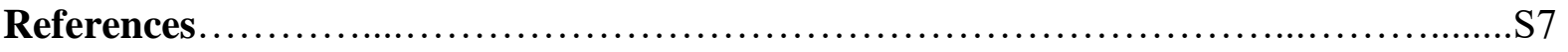



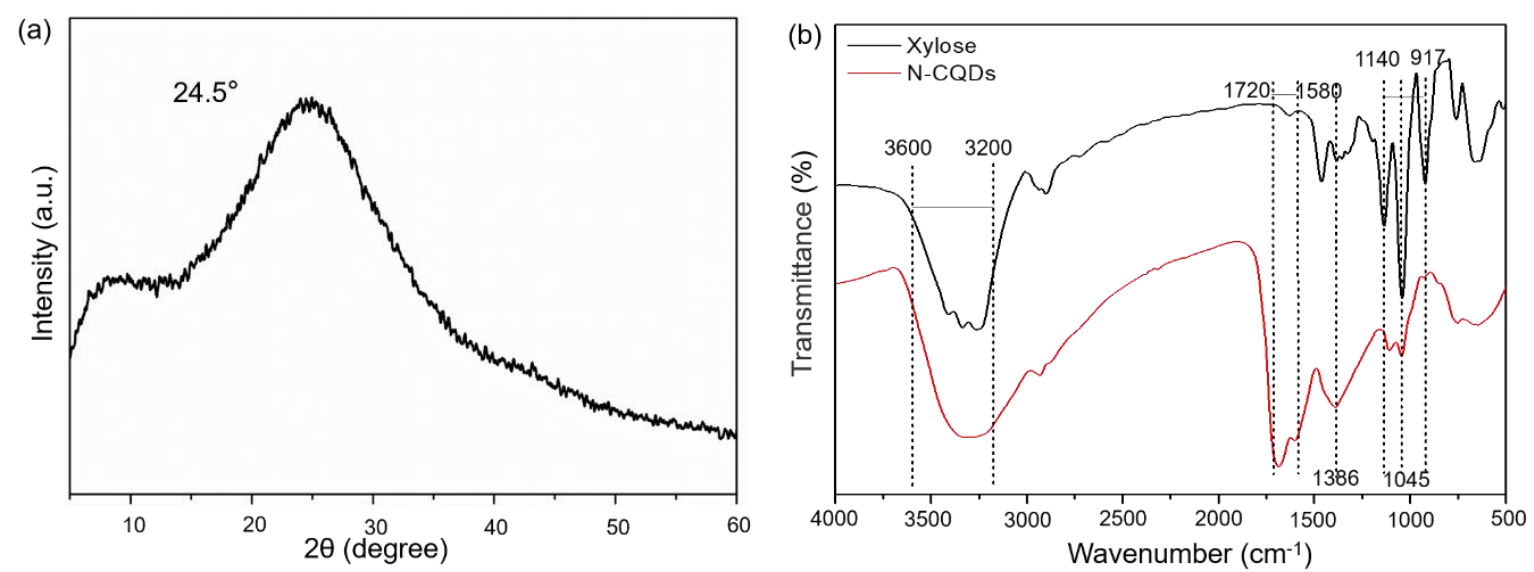

Figure S1. (a) XRD pattern of N-CQDs. (b) FT-IR spectra of xylose and N-CQDs.
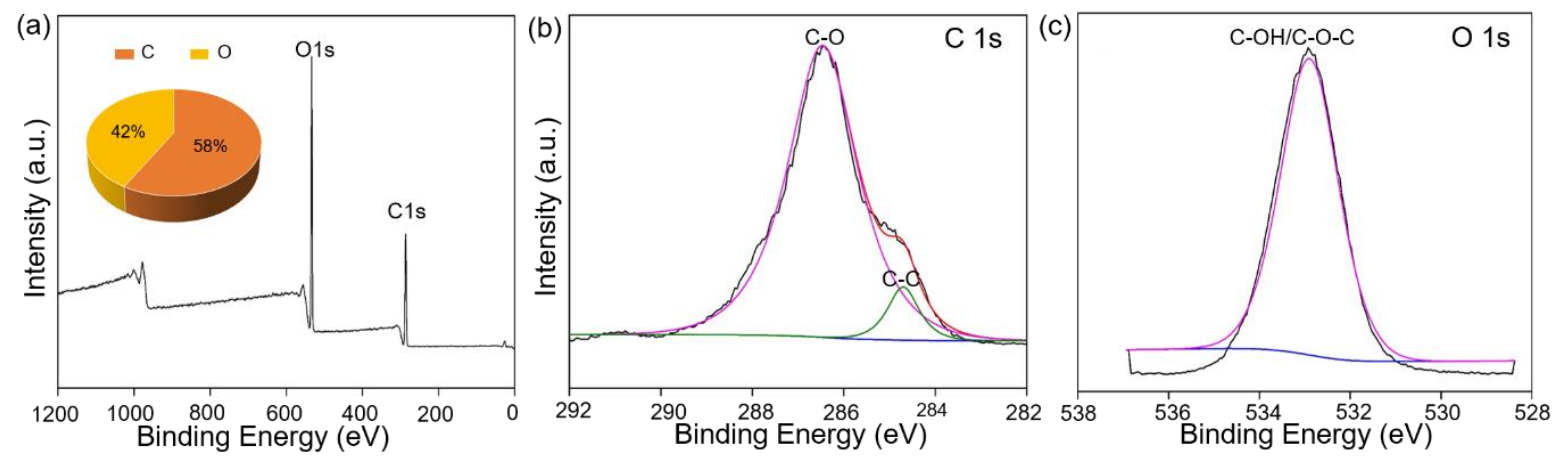

Figure S2. (a) XPS survey spectra of xylose (inset: atomic percentages of elements). High resolution XPS spectra. (b) C 1s. (c) O 1s of xylose.
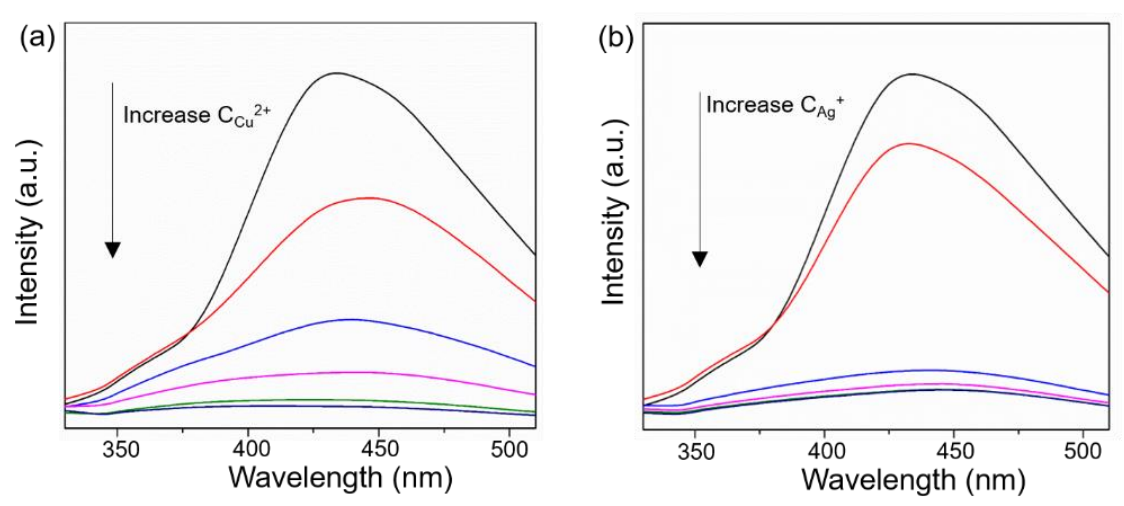

Figure S3. Gradual decrease in the fluorescence intensity of N-CQDs by increasing the concentration of (a) $\mathrm{Cu}^{2+}$ and (b) $\mathrm{Ag}^{+}$. 
(a)

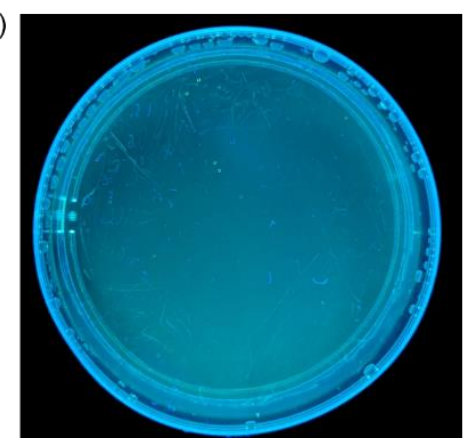

(b)

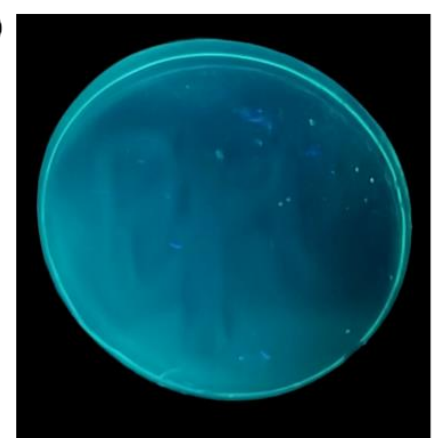

(c)

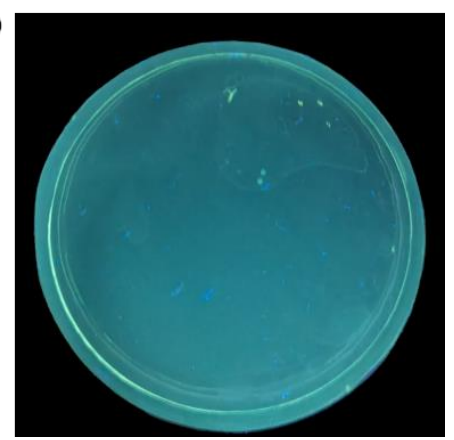

Figure S4. The photographs of SWSH in a petri dish under $365 \mathrm{~nm}$ UV light: (a) The original SWSH; (b) The "B F U" shown on the surface of SWSH by using $\mathrm{Cu}^{2+}$ solution; (c) The handwriting faded away by adding L-cys.

(a)

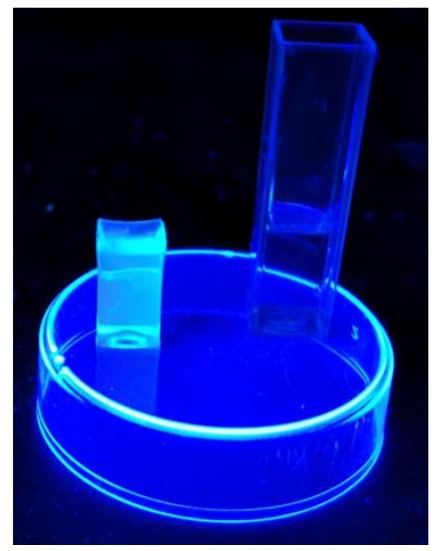

(b)



(c)

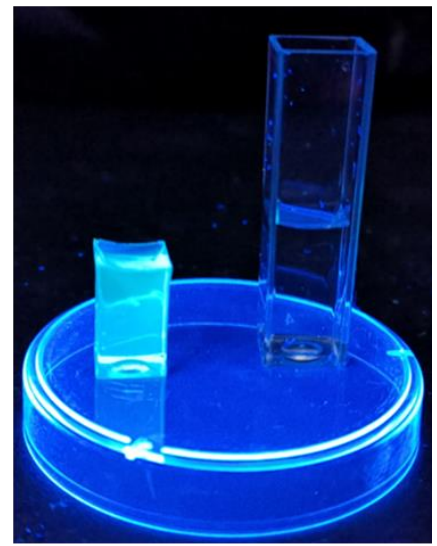

Figure S5. SWSH fluorescent carbon dots leakage test (photographs of SWSH under $365 \mathrm{~nm}$

UV light): (a) Before immersing in water; (b) Immersing in water; (c) After immersing in water for thirty minutes. 

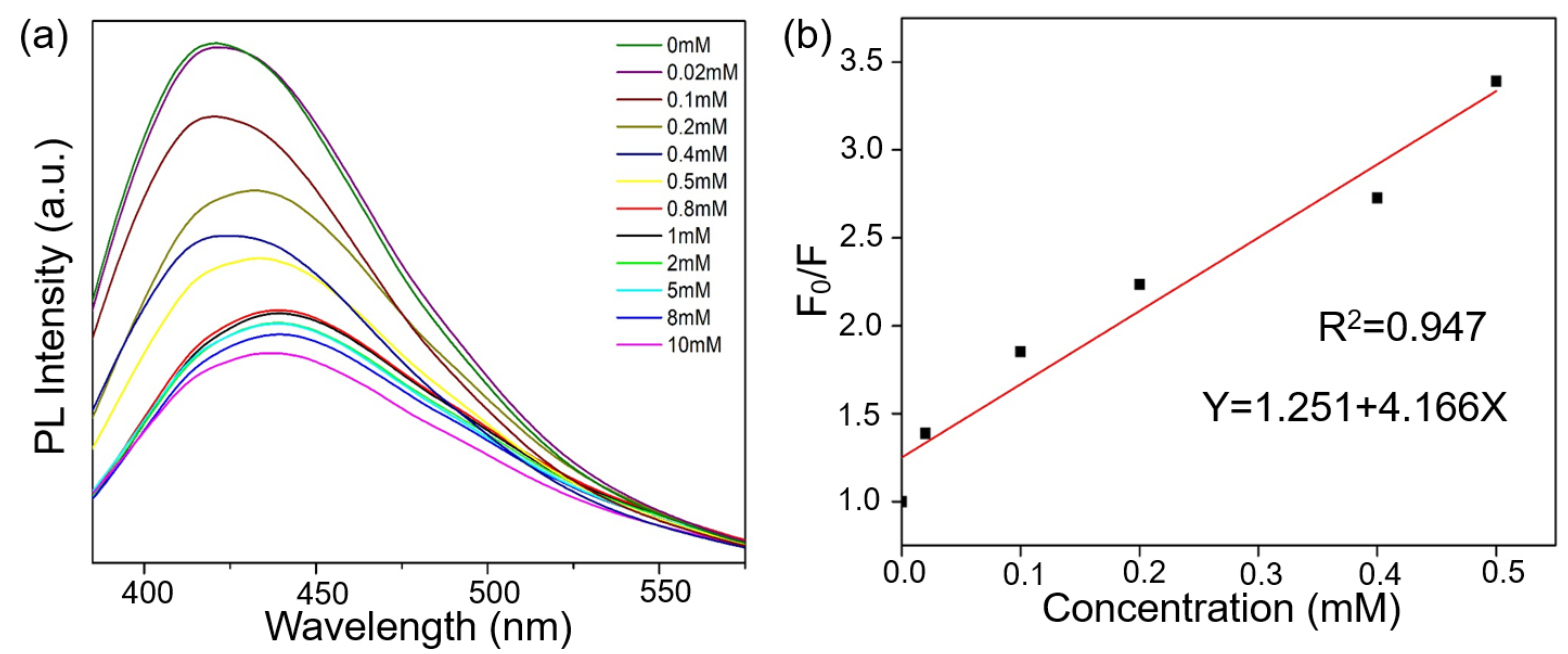

Figure S6. (a) Fluorescence response of SWSH in the presence of an increasing concentration of $\mathrm{Ag}^{+}$(from 0-10 mM). (b) The Stern-Volmer plots for the concentration of $\mathrm{Ag}^{+}$over the range from 0 to $0.5 \mathrm{mM}\left(\lambda_{\mathrm{ex}}=360 \mathrm{~nm}\right)$.

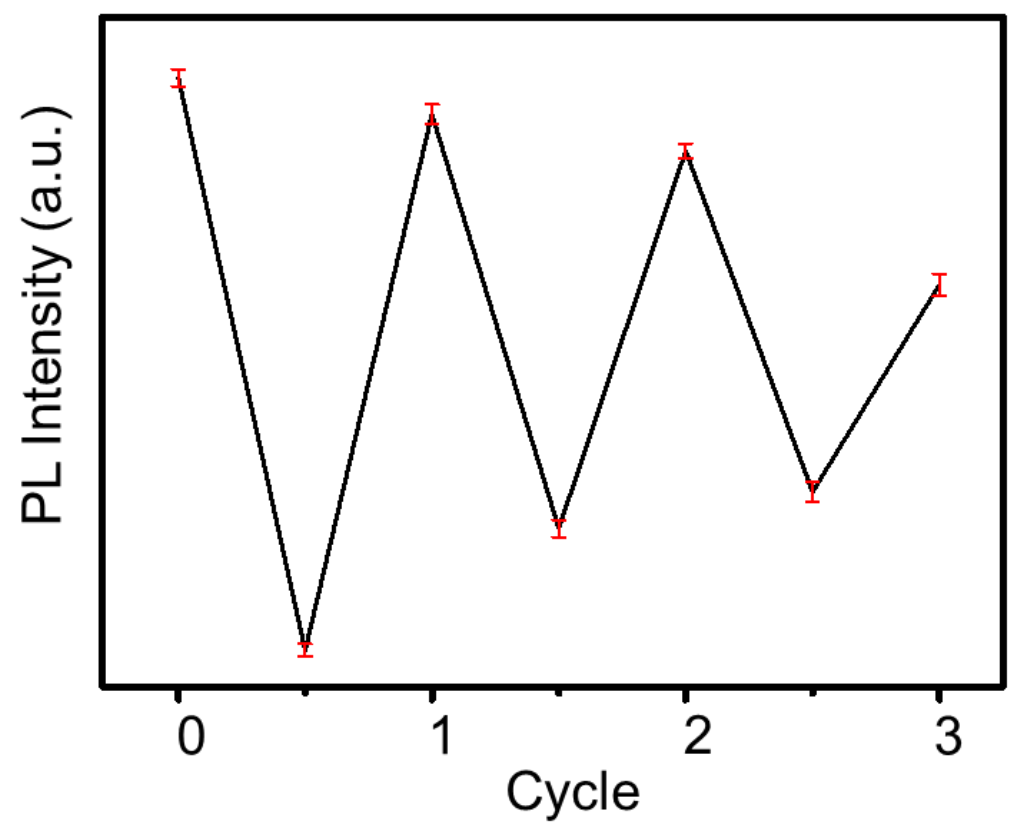

Figure S7. Fluorescence quenching and recovery cycles of SWSH. 
Table S1. Comparison of the detection limit of bimetallic ions system in different CQDs.

\begin{tabular}{|c|c|c|c|}
\hline Ions detected & $\begin{array}{c}\text { Linear range } \\
\mathbf{m M} \\
\end{array}$ & $\begin{array}{c}\text { Detect limit } \\
\mathrm{mM}\end{array}$ & Ref. \\
\hline \multirow{7}{*}{$\mathrm{Cu}^{2+}$} & $0-80.0 \times 10^{-3}$ & $0.160 \times 10^{-3}$ & 1 \\
\hline & $0-100 \times 10^{-3}$ & $1.00 \times 10^{-3}$ & 2 \\
\hline & $0.0100-100 \times 10^{-3}$ & $0.0500 \times 10^{-3}$ & 3 \\
\hline & & & \\
\hline & $0.00833-833 \times 10^{-3}$ & $0.300 \times 10^{-3}$ & 4 \\
\hline & $0-47.0 \times 10^{-3}$ & $7.78 \times 10^{-3}$ & 5 \\
\hline & $0-1000 \times 10^{-3}$ & $0.813 \times 10^{-3}$ & This work \\
\hline & $0.100-1.50 \times 10^{-3}$ & $0.0680 \times 10^{-3}$ & 6 \\
\hline & $0-700 \times 10^{-3}$ & $0.500 \times 10^{-3}$ & 7 \\
\hline \multirow{5}{*}{$\mathbf{A g}^{+}$} & $0-6.00 \times 10^{-3}$ & $0.130 \times 10^{-3}$ & 8 \\
\hline & & & \\
\hline & $0.100-130 \times 10^{-3}$ & $0.0300 \times 10^{-3}$ & 9 \\
\hline & $0.0800-10.7 \times 10^{-3}$ & $0.0100 \times 10^{-3}$ & 10 \\
\hline & $0-500 \times 10^{-3}$ & $0.468 \times 10^{-3}$ & This work \\
\hline
\end{tabular}


Table S2. Detecting of $\mathrm{Cu}^{2+}$ using SWSH in tap water.

\begin{tabular}{|c|c|c|c|c|}
\hline Samples & $\begin{array}{l}\text { Added amounts } \\
\qquad(\mathrm{mM})\end{array}$ & $\begin{array}{c}\text { Measured } \\
\text { amounts (mM) }\end{array}$ & Recovery (\%) & $\begin{array}{c}\operatorname{RSD}(\%) \\
(n=3)\end{array}$ \\
\hline \multirow{3}{*}{ Tap water } & 0.20 & 0.21 & 105 & 1.20 \\
\hline & 0.50 & 0.53 & 106 & 0.58 \\
\hline & 10.00 & 10.10 & 101 & 2.00 \\
\hline
\end{tabular}

Table S3. Detecting of $\mathrm{Ag}^{+}$using SWSH in tap water.

\begin{tabular}{ccccc}
\hline Samples & $\begin{array}{c}\text { Added amounts } \\
(\mathrm{mM})\end{array}$ & $\begin{array}{c}\text { Measured } \\
\text { amounts }(\mathrm{mM})\end{array}$ & $\begin{array}{c}\text { Recovery (\%) } \\
\text { RSD (\%) } \\
(\mathrm{n}=3)\end{array}$ & $\begin{array}{c}\text { (\%) } \\
\text { Tap water }\end{array}$ \\
0.02 & 0.019 & 95.0 & 1.60 \\
& 0.10 & 0.051 & 102 & 0.76 \\
& 0.104 & 104 & 1.40 \\
\hline
\end{tabular}




\section{References}

1. S. Dong, S. Wang, X. Wang and L. Zhai, Mater. Lett., 2020, 278, 128404.

2. A. Zhu, Q. Qu, X. Shao, B. Kong and Y. Tian, Angew. Chem. Int. Ed. Engl., 2012, 51, 7185-7189.

3. L. Shi, Y. Li, X. Li, B. Zhao, X. Wen, G. Zhang, C. Dong and S. Shuang, Biosens. Bioelectron., 2016, 77, 598-602.

4. Y. Lin, C. Wang, L. Li, H. Wang, K. Liu, K. Wang and B. Li, ACS applied materials \& interfaces, 2015, 7, 27262-27270.

5. X. W. Tan, A. N. B. Romainor, S. F. Chin and S. M. Ng, J. Anal. Appl. Pyrolysis, 2014, 105, $157-165$.

6. T. Khantaw, C. Boonmee, T. Tuntulani and W. Ngeontae, Talanta, 2013, 115, 849-856.

7. N. Arumugam and J. Kim, Mater. Lett., 2018, 219, 37-40.

8. L. Shen, M. Chen, L. Hu, X. Chen and J. Wang, Langmuir : the ACS journal of surfaces and colloids, 2013, 29, 16135-16140.

9. S. Bian, C. Shen, Y. Qian, J. Liu, F. Xi and X. Dong, Sensors Actuators B: Chem., 2017, 242, 231-237.

10. J. H. Wang, H. Q. Wang, H. L. Zhang, X. Q. Li, X. F. Hua, Y. C. Cao, Z. L. Huang and Y. D. Zhao, Anal. Bioanal. Chem., 2007, 388, 969-974. 